\title{
Reynolds stress observations in continental shelf seas
}

\author{
M.J. Howarth*, A.J. Souza \\ Proudman Oceanographic Laboratory, Joseph Proudman Building, 6 Brownlow St., Liverpool L3 5DA, UK
}

Accepted 17 January 2005

Available online 27 April 2005

\begin{abstract}
The three basic observational approaches to estimating turbulence parameters in continental shelf seas are free-fall micro-structure probes from which dissipation is inferred; fast-sample $(10-20 \mathrm{~Hz})$ current meters in sea-bed frames measuring turbulence intensity directly; and fast-sample $\mathrm{O}(1 \mathrm{~Hz})$ high-frequency Acoustic Doppler Current Profilers (ADCPs) where Reynolds stress profiles and hence turbulence production can be estimated from the variance of the along beam data. Uncertainties are associated with each approach since turbulence is a small-scale, high-frequency phenomenon and since estimates can easily be contaminated by the presence of surface waves. This paper concentrates on the latter two approaches, particularly the ADCP method, focussing on the degree of confidence that can be placed on the estimates.

Results are presented from nine experiments from six sites in the North and Irish Seas and one in the Gulf of California, involving the deployment of 0.6 and $1.2 \mathrm{MHz}$ standard broadband ADCPs mounted in sea-bed frames. The sites ranged from very tidally energetic, shallow $(20 \mathrm{~m}$ deep $)$ to low tidal energy, deeper $(110 \mathrm{~m})$. The ADCPs recorded data with a variety of sample regimes, from 2 to $0.5 \mathrm{~Hz}$; bin sizes ranged from 0.25 to $1 \mathrm{~m}$. In two of the experiments the ADCP near-bed Reynolds stress estimates were tested against independent estimates from toroidal electro-magnetic current meters measuring the three components of current (vertical and both horizontal) at $8 \mathrm{~Hz}$, deployed on a nearby frame. In all cases the correlation coefficient squared between the two sets of Reynolds stress estimates was 0.7. In a further three recent deployments, an Acoustic Doppler Velocimeter (ADV) was deployed on the bottom frame with the ADV measuring volume located within the first ADCP bin and sampling at 20 or $25 \mathrm{~Hz}$. The ADV measurements also show an explained variance of about $80 \%$ and a transfer function of about 1 during periods where waves were not present.

One objective of these studies was to test and improve representation of dissipation processes in two- and threedimensional numerical models, including the concept of the constant stress layer. At its very simplest, bottom stress is estimated from the depth-averaged flow via a quadratic drag law. Calculations from these measurements give values for the drag coefficient between 0.0006 and 0.0019 , averaging 0.0011 , smaller than the value used in most depth-averaged numerical models $(0.0025)$. There is some evidence that the value of the drag coefficient is dependent on the tidal current speed.
\end{abstract}

(C) 2005 Elsevier Ltd. All rights reserved.

\footnotetext{
*Corresponding author. Fax: +441517954801.

E-mail address: mjh@pol.ac.uk (M.J. Howarth).
} 


\section{Introduction}

Practical two-dimensional (2D) and three-dimensional (3D) hydrodynamic models of continental shelf seas are based on assumptions about the parameterisation of dissipation, and consequently of bed friction and the vertical variation of shear stress. To avoid the computational expense of describing adequately the high-shear near-bed layer, it is common for $3 \mathrm{D}$ models to parameterise bed friction via a slip bottom-boundary condition where the bed stress is given by a quadratic drag law, using a near-bed current estimate, analogous to its estimate in 2D models. Dissipation is ultimately caused by turbulence, but the associated time and space scales are too small to be included explicitly in regional models. However, the processes are fundamental, determining the principal sink for the dominant tidal and wind-forced energy, since only exceptionally is this energy propagated back into the ocean from the interior of a continental shelf sea. The parameterisations can be checked in a bulk way, for instance with tidal models against the phase and amplitude progression of coastal elevations and, more rarely of offshore currents or sea-bed pressures, or against the vertical variation of currents, particularly in the high-shear near-bed zone. (However, the quality of current-meter measurements has been such that the latter has only become convincing with the arrival of Acoustic Doppler Current Profilers, ADCPs.) Because of the smallscale nature of the processes, direct measurements to check parameterisations are very difficult.

The $x$ component of the shear stress in the equations of motion, $\tau_{x z}(z, t)$, also called the Reynolds stress, is defined as

$t_{x z}(z, t)=-\rho\left\langle u^{\prime} w^{\prime}\right\rangle$,

following decomposition of the motion into mean, denoted by \langle\rangle , and fluctuating parts, denoted by an apostrophe, suggested by Osbourne Reynolds. For tidal flows, an averaging period of the order $10-20 \mathrm{~min}$ is appropriate since this allows a sufficient population of events whilst the statistics are quasi-stationary (Soulsby, 1980; Stacey et al., 1999). Near the bed a constant stress layer is postulated in which the velocity profile is logarith- mic, and at the bed the Reynolds stress equals the bottom stress, $\tau_{\mathrm{b}}$,

$\tau_{\mathrm{b}}=\left(\tau_{x z}, \tau_{y z}\right)$.

The approach of evaluating terms like $\left\langle u^{\prime} w^{\prime}\right\rangle$ from frequent measurements of the three components of current at a point goes back at least as far as Bowden and Fairbairn (1956), where highfrequency measurements were made with electromagnetic current meters mounted in bed frames. The target is to sample at least at $10 \mathrm{~Hz}$, if appropriate, since the size of the sampling volume sets an upper limit to a meaningful sample rate. The method requires the current meters to be fixed and so has only been attempted by deploying current meters in a frame sitting on the sea bed, the sensors usually being in the bottom $1 \mathrm{~m}$.

Two techniques are applicable for fast-sample current measurement-electro-magnetic and acoustic. The first to achieve success were electro-magnetic sensors, although experience has shown several drawbacks. The heads are intrusive, so that whatever the sensor's shape (spherical, discus, toroidal) flow separation can occur in accelerating/decelerating flows. A toroidal shape has been shown to minimise these effects. Electromagnetic sensors need tender loving care, and are subject to drift in their calibrations and to variable offsets. However, experience gained over the years with electro-magnetic current meters has enabled confidence to be placed in the estimates. More recently Acoustic Doppler Velocimeters (ADVs) have become available commercially, are not affected by these problems, and also can have smaller measurement volumes and thus can sensibly be sampled faster. A bonus with these instruments is that the three components of turbulence intensity (and hence the degree of anisotropy) can be estimated. This is not possible with the ADCP method, unless the ADCP is fitted with a vertical beam, but is important for interpretation of the results.

A generic difficulty associated with any current sensor mounted on a frame is that flow from certain directions may be affected by the structure of the frame. Also whatever the sensor, the Reynolds stress calculation is sensitive to the correct determination of the vertical but is not 
sensitive to the presence of waves, since $\left\langle u^{\prime} w^{\prime}\right\rangle$ and $\left\langle v^{\prime} w^{\prime}\right\rangle$ are zero for wave orbital velocities, as the horizontal and vertical components are in quadrature.

The introduction of high-frequency $(\sim 1 \mathrm{MHz})$ incoherent broadband ADCPs with large memory capacities has enabled a new method of estimating Reynolds stress. The ADCP can record fastsample $(\sim 0.5-1 \mathrm{~Hz})$ measurements of current structure with a vertical resolution of $\sim 0.25-1 \mathrm{~m}$ for a month or longer, with sufficient sampling accuracy to be practical. Since the instrument is self-contained, it can be deployed anywhere and does not need connecting to the shore or a ship, often a limitation for fast-sample measurements. Because of the nature of the method, sample rates cannot be increased dramatically; that is possible with pulse-to-pulse coherent dopplers or with acoustic velocimeters, for instance, both of which also make measurements with smaller space scales. Measurement at these rates enables estimation of the variation with height above the sea bed of the Reynolds stress from the variance in the alongbeam measurements, for instance Stacey et al. (1999), Lohrmann et al. (1990), Lu and Lueck (1999), Lu et al. (2000). The method is outlined below; for a full derivation see Lohrmann et al. (1990) and Lu and Lueck (1999).

A common ADCP configuration has four acoustic beams at right angles to each other in plan view, each beam pointing at the same angle, $\theta$, to the vertical, usually either $20^{\circ}$ or $30^{\circ}$. The components of current measured along each of the four beams will be denoted by $b_{1}, b_{2}, b_{3}, b_{4}$, with beams 1 and 2 opposite each other in the $y(v)$ direction and beams 3 and 4 in the $x(u)$ direction. The horizontal, $u$, and vertical, $w$, components of velocity can be estimated from measurements along beams 3 and 4 provided that they are homogeneous over the distance of the beam separation (of order $15 \mathrm{~m}$ at $20 \mathrm{~m}$ range for $\left.\theta=20^{\circ}\right)$. This is true for the mean values where $\left\langle u_{1}\right\rangle=-\left\langle u_{2}\right\rangle,\left\langle u_{3}\right\rangle=-\left\langle u_{4}\right\rangle$, but is not true for the fluctuation $u^{\prime}, v^{\prime}, w^{\prime}$, since each of the beams will be sampling different eddies. Hence it is impossible to calculate $\left\langle u^{\prime} w^{\prime}\right\rangle$ directly. However, all is not lost since the correlator $\left\langle u^{\prime} w^{\prime}\right\rangle$ can be estimated from the variances in the along-beam records if all second-order moments of turbulent velocity fluctuations are assumed to be horizontally homogeneous over the beam separation (i.e. $\left\langle u_{1}^{\prime 2}\right\rangle=\left\langle u_{2}^{\prime 2}\right\rangle,\left\langle u_{1}^{\prime} w_{1}^{\prime}{ }_{1}\right\rangle=\left\langle u_{2}^{\prime} w_{2}^{\prime}{ }_{2}\right\rangle$, etc.). In that case

$$
\begin{aligned}
-\left\langle u^{\prime} w^{\prime}\right\rangle= & \left(\left\langle b_{4}^{\prime 2}\right\rangle-\left\langle b_{3}^{\prime 2}\right\rangle\right) /(2 \sin 2 \theta) \\
& -\varphi_{2}\left\langle u^{\prime 2}-w^{\prime 2}\right\rangle+\varphi_{3}\left\langle u^{\prime} v^{\prime}\right\rangle
\end{aligned}
$$

and similarly for $-\left\langle v^{\prime} w^{\prime}\right\rangle . \varphi_{2}$ and $\varphi_{3}$ are the ADCP pitch and roll angles.

Because the currents are measured in beam coordinates, tilt is not automatically corrected. The correction terms ( 2 and 3 on the right-hand side of the equations) cannot be calculated since this method does not give estimates of $\left\langle u^{\prime 2}\right\rangle,\left\langle v^{\prime 2}\right\rangle$, $\left\langle w^{\prime 2}\right\rangle,\left\langle u^{\prime} v^{\prime}\right\rangle$. For pitch and roll angles less than a few degrees or if the turbulence is only weakly anisotropic, this bias will be small ( $\mathrm{Lu}$ and Lueck, 1999; Howarth, 2002).

The method breaks down in the presence of surface or internal waves, since these will also lead to large along-beam variances. Indeed for surface waves, data from the near-surface bins are now applied to determining the directional properties of the waves. Even near the bed the horizontal variance, $\left\langle u^{\prime 2}\right\rangle,\left\langle v^{\prime 2}\right\rangle$, can be large so that contributions from this source may become significant (Lohrmann et al., 1990).

In principle, the ADCP sampling scheme may lead to the Reynolds stress being underestimated, particularly for longer sample intervals $(2 \mathrm{~s})$ and to a lesser extent for larger bin sizes $(1 \mathrm{~m})$, by $\sim 30 \%$ (Rippeth, et al., 2002). Balanced against this are the larger uncertainties associated with smaller bin sizes, especially, and faster sampling (for a fuller discussion see Williams and Simpson, 2004).

Uniquely, the profile of Reynolds stress is estimated over the measurement range of the ADCP. However, in open-sea situations only the lower estimates are reliable (and for upwardlooking ADCPs it is difficult to get the lowest bin below $1 \mathrm{~m}$ ), since noise increases with height because of surface waves and also the beams become further apart.

On its own the method does not give an estimate of the turbulent kinetic energy density

$\left(\left\langle u^{\prime 2}\right\rangle+\left\langle v^{\prime 2}\right\rangle+\left\langle w^{\prime 2}\right\rangle\right) / 2$. 
To determine this an estimate is also needed of the turbulence anisotropy, for instance given by

$\left\langle w^{\prime 2}\right\rangle /\left(\left\langle u^{\prime 2}\right\rangle+\left\langle v^{\prime 2}\right\rangle\right)$

(see Lu and Lueck, 1999), which varies between zero for anistropic turbulence and 0.5 for isotropic turbulence. One extra measurement is needed to determine the the density, for instance if the ADCP is fitted with a fifth beam pointing vertically upwards measuring $w^{\prime}$ directly.

Since Reynolds stress measurements are difficult to make with other means, if this application for ADCPs is shown to be reliable, in the sense of returning good-quality estimates, it will be invaluable. However, a difficulty faced throughout is of assessing the quality and content of the estimates, since there is no method for measuring bottom stress from first principles. This paper is in two parts, the first reviews five comparisons between ADCPs and fast-sample current meter estimates of Reynolds stress establishing the validity of the method. The second, compares the ADCP estimates against $\mathbf{u}|\mathbf{u}|$, from the depth-averaged current. This is a first-order check, available directly from the time-averaged ADCP current data; along the lines of a quadratic drag law, with the bonus of estimating a drag coefficient. The details of small-scale processes are ignored but significant discrepancies will need justification.

In addition, the bottom stress can be estimated by bulk methods based on current measurements averaged over several minutes - the quadratic drag law, fitting a logarithmic profile (Lueck and Lu, 1997) or balancing the depth-averaged equations of motion

\section{Measurements}

Since 1998, the technique has been applied in eight experiments in the Irish and North Seas and one in the Gulf of California (in contrast to most reports in the literature where the measurements are in channels). The sites ranged from high tidal energy, shallow (20 m deep) to low tidal energy, deeper $(110 \mathrm{~m})$, although at all sites the semidiurnal tides are the dominant motion. The range in $M_{2}$ maximum current amplitude is more than a factor of 7 .

In two of the experiments, the ADCP estimates of Reynolds stress were compared with direct estimates from electro-magnetic current meter measurements, sampled at $8 \mathrm{~Hz}$ (Howarth, 2002, 2003) and in a further three to estimates from ADVs recording at 20 or $25 \mathrm{~Hz}$. In addition, the three components of turbulence intensity (and hence the degree of anisotropy) were estimated from the current meter records. The water depths, tidal current speeds and record durations are listed in Table 2. Site 7 was in the Gulf of California (Souza et al., 2004), site 2 in the northern North Sea, site 3 in the southern North Sea, and the remainder in the Irish Sea-site 1 in Red Wharf Bay, off the east coast of Anglesey (Rippeth et al., 2003), sites 4 and 5 in Liverpool Bay (Souza and Howarth, 2005), site 6 off Holyhead, west of Anglesey (see Fig. 1 for a map of the sites around the UK).

1.2 $\mathrm{MHz}$ broadband ADCPs and/or $600 \mathrm{kHz}$ ADCP at sites 5 and 6 were mounted in sea-bed frames, to provide a stable environment for the measurements, greatly to the benefit of the data analysis since we are working in beam coordinates. The ADCPs recorded data with a variety of sample regimes, from $2 \mathrm{~Hz}$ (recording every ping) to $0.5 \mathrm{~Hz}$ (averaging over four, five or six pings). The instruments were set up to record in Mode 1, which has the property that the noise characteristics can be assumed to be independent of the velocities measured (RDI, 2000), except at sites 5 and 6, which used Mode 12, to allow faster sampling (8 subpings per second). In two cases burst sampling was used to give a duration of about 50 days. Bin sizes ranged from 0.25 to $1 \mathrm{~m}$, with measurements covering the near bed $10-20 \mathrm{~m}$.

Electro-magnetic current meters were deployed at two-sites - site 2 a low-energy site and site 4 a more energetic site. The current meters were mounted on a $2 \mathrm{~m}$ high tripod bottom frame, STABLE, at $0.3,0.6$ and $0.9 \mathrm{~m}$ above the bed. Although these heights are below the lowest ADCP bin (a $1 \mathrm{~m}$ bin centred at $2 \mathrm{~m}$ above the bed for site 2 and a $0.5 \mathrm{~m}$ bin centred at $1.65 \mathrm{~m}$ above the bed for site 4), since a constant stress layer is expected the difference in heights should 


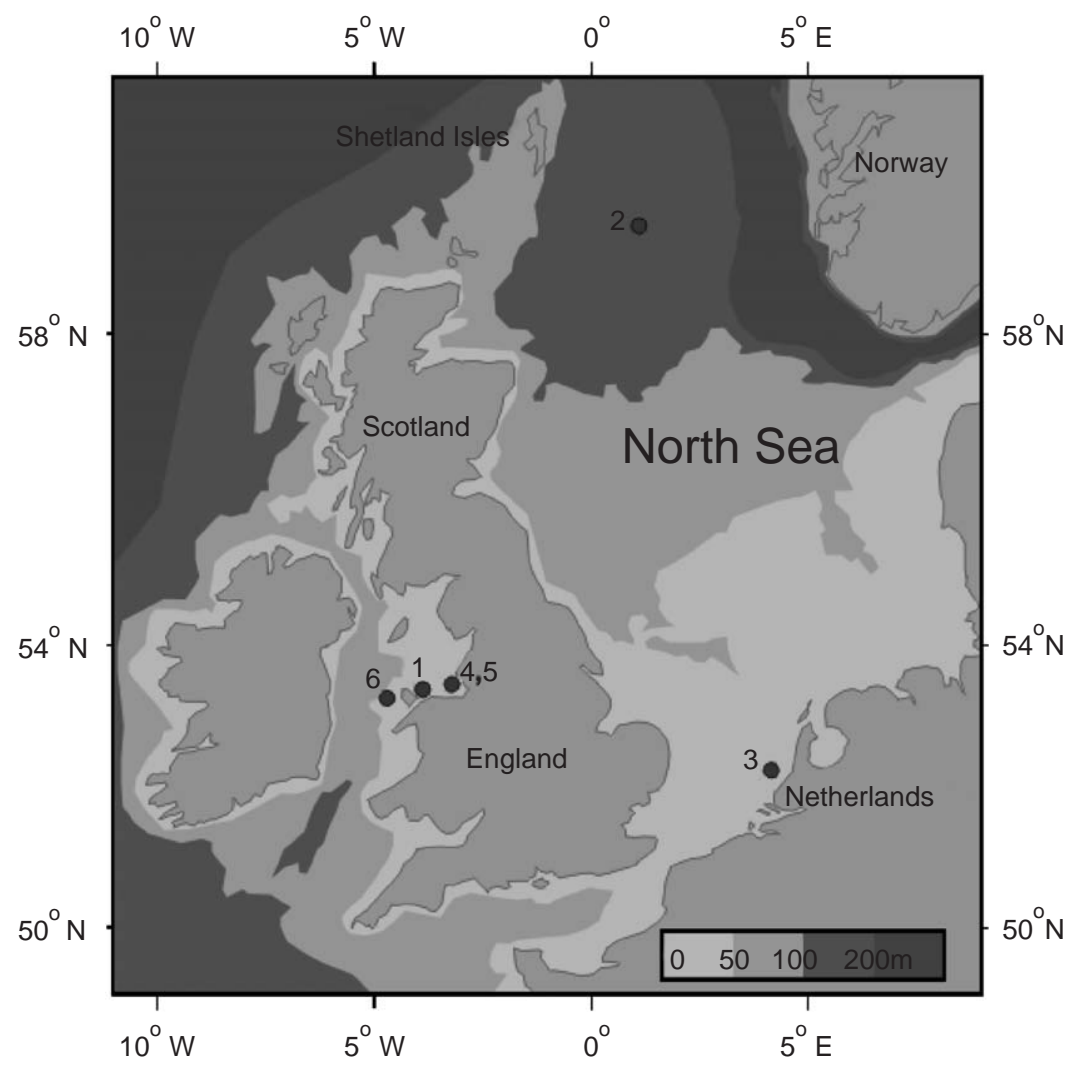

Fig. 1. Map showing experiment locations around the UK. Site 2 was in the northern North Sea, site 3 in the southern North Sea and the remainder in the Irish Sea - site 1 in Red Wharf Bay, off the east coast of Anglesey, and sites 4 and 5 in Liverpool Bay, site 6 was off Holyhead, to the west of Anglesey.

not introduce significant errors. The current meter heads were $0.17 \mathrm{~m}$ diameter toroids, each having two pairs of electrodes measuring two perpendicular components of current. Pairs of heads were mounted at right angles (denoted port and starboard), with each head sampling a horizontal and the vertical component of current. Data were recorded at $8 \mathrm{~Hz}$ in bursts of 20 min every hour at site 2 and $40 \mathrm{~min}$ every hour at site 4 . In these comparisons the ADCP and current meters were mounted on separate frames that were deployed up to $1 \mathrm{~km}$ apart. Details of the comparisons are given in Howarth $(2002,2003)$, especially of the data quality.

In further three recent deployments, a $5 \mathrm{MHz}$ ADV sampling at 20 or $25 \mathrm{~Hz}$ was deployed on the ADCP frame with the ADV measuring volume located within the first ADCP bin (Souza and Howarth, 2005).

Wave activity was not significant during any of the experiments whose results are presented here, partly because the majority were conducted in summer. Confirmation of this was provided at sites 2, 4, 5ii and 6 by the records from the fast sampling current meters that contained little energy at wave frequencies. However, results from only part of the record (27 days) from deployment 5 ii have been included since there was a clear indication for the first 14 days that wave activity from two storms had affected the quality of the ADCP estimates (this is the subject of further study). The conclusions here, therefore, only apply to times of low wave activity. 


\section{Synthesis current meter and ADCP estimates}

Both the ADCP and current meter records were analysed with a basic averaging period of $10 \mathrm{~min}$. Values of Reynolds stress are given throughout in units of $\mathrm{m}^{2} \mathrm{~s}^{-2}$ and should be multiplied by the water density $\left(\sim 1027 \mathrm{~kg} \mathrm{~m}^{-3}\right)$ for conversion to Pascals. For both the electro-magnetic current meter comparisons only one component was applicable (fortunately in each case containing most of the signal) since in one case one set of the electro-magnetic current meters was in disturbed flow and in the other only three ADCP beams were recorded. For the ADV comparisons both components were available and so complex correlations were calculated.

Fig. 2 shows a typical time series of Reynolds stress comparison, for site 4 (Liverpool Bay) from the bottom ADCP bin (at $1.65 \mathrm{~m}$ ) along $127^{\circ}$ (only three beams worked for this deployment and the orientation of the $M_{2}$ ellipse was along $98^{\circ}$ ) and the corresponding component from the current meters. Both lines show the same details - flood peak higher than ebb (this asymmetry will be discussed later), shoulder near slack wateralthough the ADCP record is noisier because a small bin size $(0.5 \mathrm{~m})$ was used. There appears to

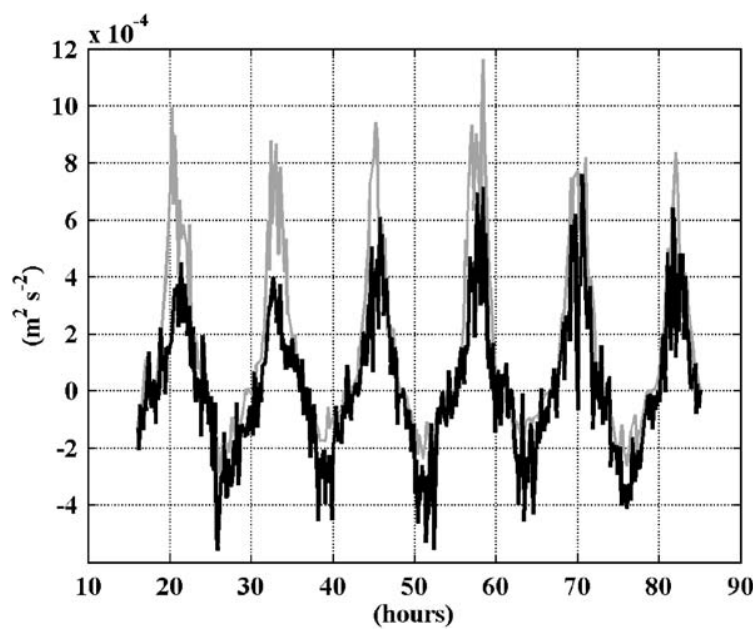

Fig. 2. Time series of one component (along $127^{\circ}$ ) of Reynolds stress estimates from Liverpool Bay (site 4): black $1.2 \mathrm{MHz}$ ADCP recording an ensemble of two pings every second, grey electro-magnetic current meter. be an offset between the ADCP and current meter estimates of about $1 \times 10^{-4} \mathrm{~m}^{2} \mathrm{~s}^{-2}$, in a measurement range of $1 \times 10^{-3} \mathrm{~m}^{2} \mathrm{~s}^{-2}$. The reason for the offset is not clear. (No similar offsets were detected in the other comparisons.)

Scatter plot comparisons from three sites with increasing Reynolds stress are shown in Fig. 3, from (a) $1 \times 10^{-4} \mathrm{~m}^{2} \mathrm{~s}^{-2}$ to (c,d) $7 \times 10^{-3} \mathrm{~m}^{2} \mathrm{~s}^{-2}$ (Fig. 3B shows the same data and hence the same features as in Fig. 2). The current meter estimates are plotted in the $x$-direction and ADCP estimates in the $y$-direction. Electro-magnetic current meters were used for Figs. 3A and B and an ADV for Fig. $3 \mathrm{C}$. The quality of the correlation appears to be as good for low Reynolds stress regimes (Fig. 3A) as for high (Fig. 3C,D). Table 1 contains a summary of all the ADCP and current-meter Reynolds stress comparisons. The amount of variance explained by the comparisons ranged between $68 \%$ and $87 \%$. The ADV comparisons returned better correlations, all with $r^{2}>0.8$, probably because the ADV measurement cell was co-located (both horizontally and vertically) with the bottom ADCP bin but maybe also reflecting the higher ADV sample rate. The slopes of the linear regressions are in the vicinity of unity, indicating that the magnitude of the ADCP estimates is similar to that from the current meters and does not appear to be an under-estimate (see the introduction), although with very few comparisons the uncertainties are still large. In particular, for what should be the more realistic ADV comparisons the slope is $1 \pm 25 \%$. The table and plots demonstrate that the method of estimating Reynolds stress from the variance in the along-beam ADCP data is viable.

The next two paragraphs discuss additional information provided by the current meters and not available from the ADCP measurements. The estimates of the three components of turbulent intensity from the current meters for deployment 4 (Irish Sea) were used to assess which of the two neglected pitch and roll error terms, $\left\langle u^{\prime 2}-w^{\prime 2}\right\rangle$ or $\left\langle u^{\prime} v^{\prime}\right\rangle$, see Section 1, were likely to be more important. The magnitude of the $\left\langle u^{\prime 2}-w^{\prime 2}\right\rangle$ and $\left\langle v^{\prime 2}-w^{\prime 2}\right\rangle$ terms were several times that of the corresponding Reynolds stress component, whereas the magnitude of the $\left\langle u^{\prime} v^{\prime}\right\rangle$ term was 


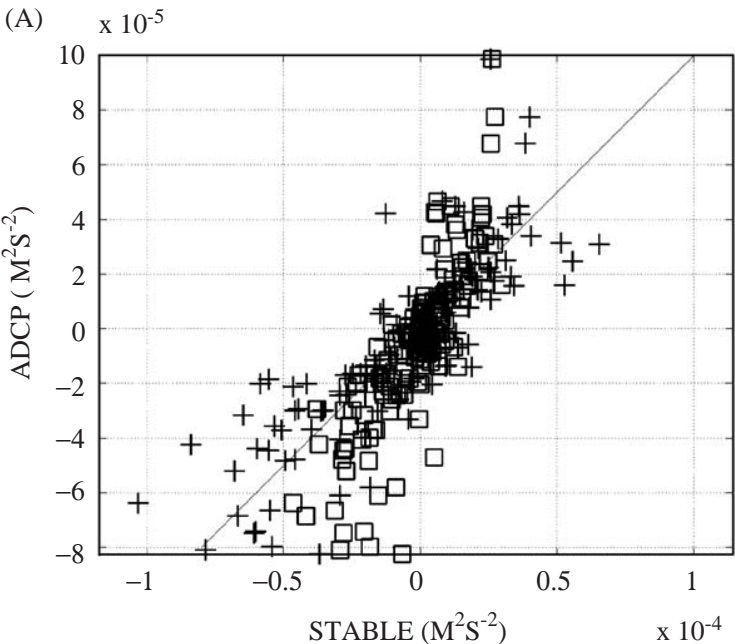

(C)

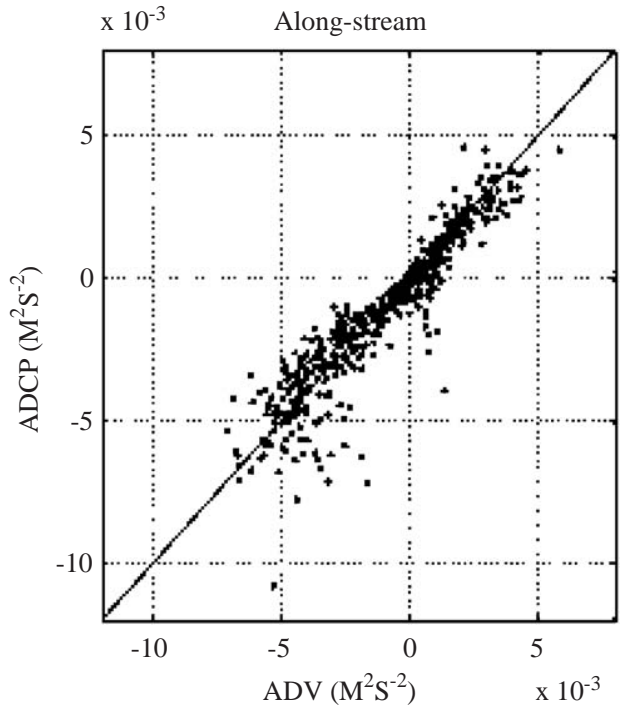

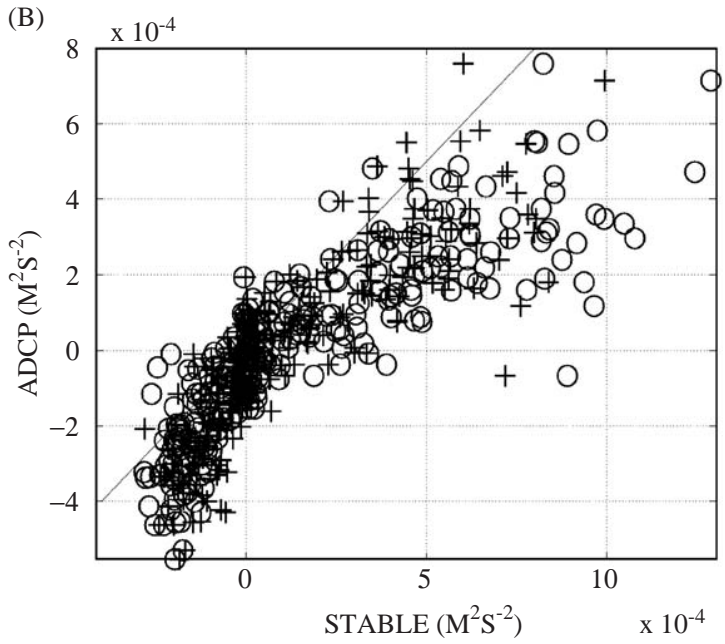

(D)

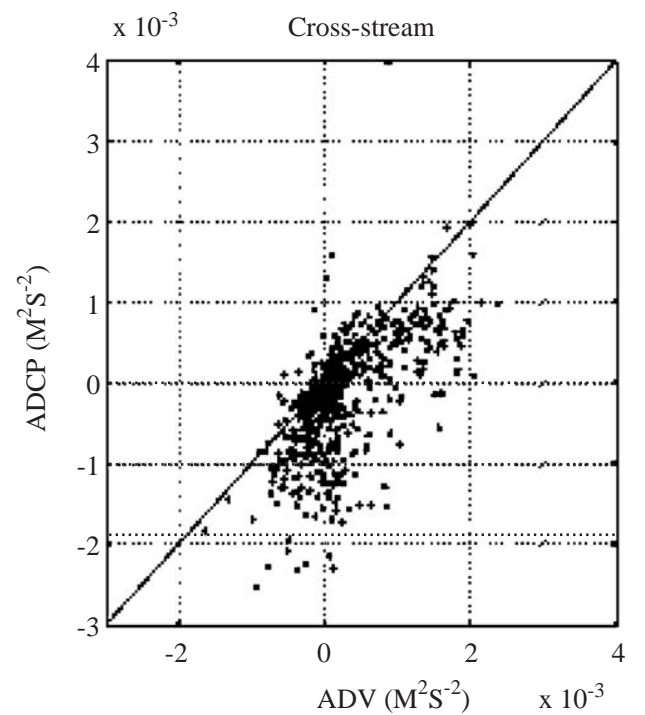

Fig. 3. Scatter plots of ADCP estimates of Reynolds stress ( $y$-axis) vs. current meter estimates ( $x$-axis) from three experiments going from weak to strong tidal currents. (A) Northern North Sea (site 2), 1.2 MHz ADCP sampling an ensemble of five pings every $2 \mathrm{~s}$ against electro-magnetic current meters at $0.6 \mathrm{~m} \mathrm{(+)}$ and $0.3 \mathrm{~m}(\square)$ above the bed; (B) Liverpool Bay (site 4), $1.2 \mathrm{MHz}$ ADCP recording an ensemble of two pings every second against electro-magnetic current meters at $0.9 \mathrm{~m}(O)$ and $0.6 \mathrm{~m}(+)$ above the bed; $(\mathrm{C})$ along stream and (D) across stream off Holyhead (site 6ii), $600 \mathrm{kHz}$ ADCP in mode 12 against an ADV. The line with unit slope is shown for reference.

significantly less. As an example, Fig. 4 shows the magnitude of the $\left\langle u^{\prime 2}-w^{\prime 2}\right\rangle$ (plus) and $\left\langle u^{\prime} v^{\prime}\right\rangle$ (circle) terms for the middle port electro-magnetic current meter (aligned within a few degrees with the rectilinear tidal flow) plotted against the magnitude of the corresponding Reynolds stress component. The same picture regarding the $\left\langle u^{\prime 2}-\right.$ $\left.w^{\prime 2}\right\rangle$ term, the only one which could be calculated, held for the North Sea deployment (2). An order of magnitude estimate suggests that, for the Irish Sea deployment, the error in the Reynolds stress calculation from this source for every $1^{\circ}$ in pitch/ roll would be $6 \%$ and for the North Sea deployment, where the tidal currents were weaker, 
Table 1

Regression of ADCP against current meter Reynolds stress estimates (e-m denotes electro-magnetic current meters on a separate sea bed frame; ADV denotes Acoustic Doppler Current meters mounted on the ADCP frame)

\begin{tabular}{llll}
\hline Site & Current meter & $r^{2}$ & Slope \\
\hline $2(\mathrm{~m})$ & e-m & 0.68 & 0.84 \\
$2(\mathrm{~b})$ & e-m & 0.68 & 1.60 \\
$4(\mathrm{t})$ & e-m & 0.72 & 0.59 \\
$4(\mathrm{~m})$ & e-m & 0.71 & 0.76 \\
$5 \mathrm{ii}$ & ADV & 0.80 & 0.83 \\
6i & ADV & 0.87 & 1.25 \\
6ii & ADV & 0.84 & 0.90 \\
\hline
\end{tabular}

$r^{2}$ is the correlation coefficient squared (the amount of variance accounted for by the correlation) and the slope is the slope of a linear regression.

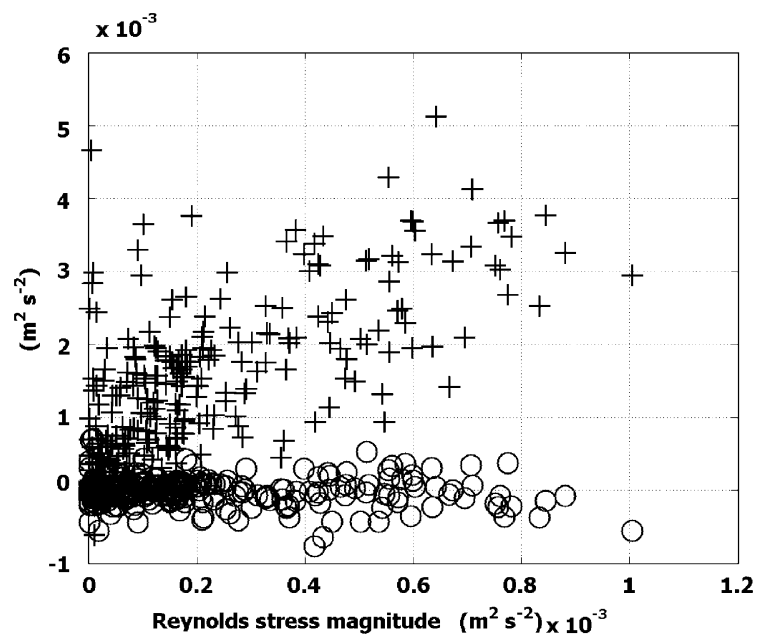

Fig. 4. The magnitude of the tilt correction terms from Liverpool Bay (site 4), from the middle $(0.6 \mathrm{~m})$ port current meter: $+\left(\left\langle u^{\prime 2}\right\rangle-\left\langle w^{\prime 2}\right\rangle\right)$ term, $\mathrm{O}\left\langle u^{\prime} v^{\prime}\right\rangle$ term.

would be $13 \%$ error. The average measured pitch and roll for the Irish Sea was $0.5^{\circ}$ and $1.2^{\circ}$, respectively, each with a standard deviation of $0.4^{\circ}$ (see also Lu and Lueck, 1999 for a discussion).

For the Holyhead deployment (6) the three components of turbulent intensity were estimated from the ADV current meter measurements. The degree of anisotropy, $\left\langle w^{\prime 2}\right\rangle /\left(\left\langle u^{\prime 2}\right\rangle+\left\langle v^{\prime 2}\right\rangle\right)$, Fig. 5 show interesting structure, lying between 0 (anisotropic, with small vertical relative to horizontal

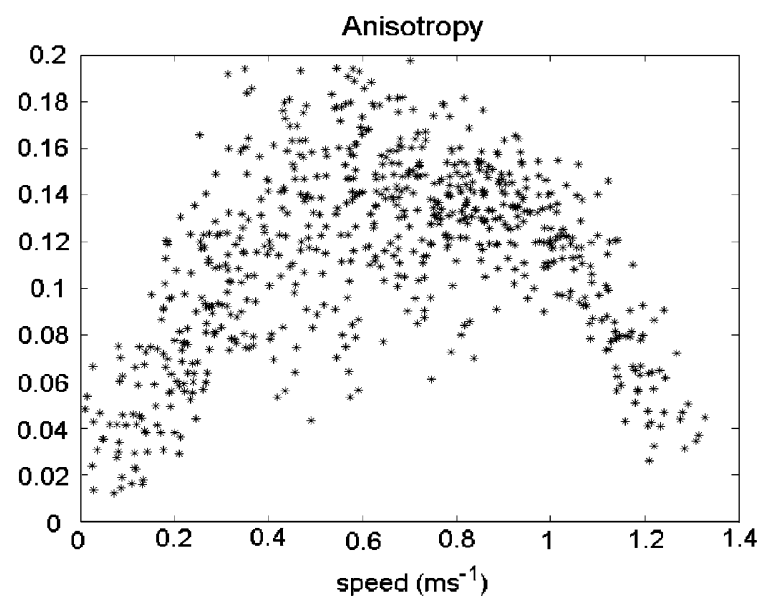

Fig. 5. Anisotropy, $\left\langle w^{\prime 2}\right\rangle /\left(\left\langle u^{\prime 2}\right\rangle+\left\langle v^{2}\right\rangle\right)$, from the Holyhead (site 6ii) plotted against the current speed.

turbulent intensity) at both low and high speeds rising to 0.2 for medium current speeds at this site $\sim 0.7 \mathrm{~m} \mathrm{~s}^{-1}$. For the Irish Sea deployment (3) values averaged around 0.2 , which seems to be common for shelf sea deployments, see also Stacey et al. (1999), with no variation with the current speed. Estimates of anisotropy are on the periphery of this paper but will clearly repay further study. Here biases may have been introduced in the estimates since neither instrumental noise nor wave energy has been subtracted. (Even low levels of wave activity can introduce significant errors to this estimate of total turbulent intensity.) At this stage ADV and ADCP measurements still complement each other.

\section{Bottom stress}

Most 3D models retain a slip bottom-boundary condition, since resolution of the benthic boundary layer (especially the high shears in the bottom few metres) is computationally very demanding. The form of the condition is for bottom stress,

$\tau_{\mathrm{b}}=\rho C_{\mathrm{d}} \mathbf{u}|\mathbf{u}|$.

The drag coefficient, $C_{\mathrm{d}}$, varies with the height of the estimating current, with the sea-bed composition, for instance parameterised by the 
roughness length, $z_{0}$, and probably with time over a tidal cycle. In a logarithmic layer

$C_{\mathrm{d}}(z)=\kappa^{2} /\left[\ln \left(z / z_{0}\right)\right]^{2}$,

where $\kappa$ is von Karman's constant $(=0.4)$. Literature values for $z_{0}$ range between $6 \times 10^{-3} \mathrm{~m}$ (sand ripples/gravel) and $5 \times 10^{-5} \mathrm{~m}$ (silt/sand) (Soulsby, 1983). However, in most models space and time variations are ignored; typical values that reproduce the tides well are $C_{\mathrm{d}}=0.0025$ for $2 \mathrm{D}$ (depth-averaged models) and $C_{\mathrm{d}}=0.01$ for the near-bed current in 3D models (Davies et al., 1997). With such values the spatial distribution over the shelf seas around the UK of dissipation per unit area for the $M_{2}$ tide varies by several decades, from less than 0.01 to greater than 1 and exceptionally up to $10 \mathrm{~W} \mathrm{~m}^{-2}$ (Flather, 1976).

The ADCP measurements enable estimation of the drag coefficient from the above by regressing the estimate of Reynolds stress from the bottom bin (the bottom stress) against $\mathbf{u}|\mathbf{u}|$, where $\mathbf{u}$ is the depth-averaged current. The depth-averaged current was chosen since it is more stable for measuring currents than the alternative reference height of $1 \mathrm{~m}$. The results are summarised in Table 2 and a sample scatter plot is shown in Fig. 6. (The various comparisons showed that there was no significant time delay or direction difference between the $\mathbf{u}|\mathbf{u}|$ series and the ADCP bottom stress estimate.) The regressions account for between $60 \%$ and $94 \%$ of the variance. The drag coefficients fall in a fairly narrow range, $0.6-1.9 \times 10^{-3}$, with a mean of $1.1 \times 10^{-3}$. The narrow range might be a reflection that, despite the differing depths and tidal conditions, the sea beds were in most cases composed of some combination of mud and sand (although the detailed composition is not known). The value is substantially less than that commonly used in depth-averaged numerical models $(0.0025)$, but similar low values have been observed before, for example (Wolf, 1999). The measurements cover a wide range of tidal current speeds, maximum $M_{2}$ amplitudes from 0.19 to $1.46 \mathrm{~m} \mathrm{~s}^{-1}$, with a suggestion from the nine data points that the drag coefficient may depend on the tidal current speed $\left(r^{2}=0.72\right.$, giving $\left.C_{\mathrm{d}}=0.001 \times\left[0.59+0.78 \times M_{2}\right]\right)$.

Two possible explanations for the difference between the model and estimated drag coefficients are firstly the models use a spatial average over a large sea area, which will be biased towards high dissipation areas (i.e. strong tidal currents) since dissipation is non-linear. Secondly, and just as important, the two values are not strictly comparable. The estimated value results from purely local processes dominated by skin friction, whilst the models are dealing in averages over a grid box which will include additional sources for drag such as form drag, for instance from sandwaves.

An alternative method for estimating the bottom stress based on bulk parameterisation is to fit a logarithmic curve, applicable to the benthic constant stress layer, to the current profile in the water column (Gross and Nowell, 1983; Lueck and $\mathrm{Lu}, 1997)$.

$u=u_{*} / \kappa \ln \left(z / z_{0}\right)$,

Table 2

Estimated drag coefficients, $C_{\mathrm{d}}$, by regressing Reynolds stress against the $|\mathbf{u}| \mathbf{u}$, where $\mathbf{u}$ is the depth-averaged current

\begin{tabular}{|c|c|c|c|c|c|}
\hline Site & Water depth (m) & $\begin{array}{l}M_{2} \max . \text { amplitude } \\
\left(\mathrm{m} \mathrm{s}^{-1}\right)\end{array}$ & $\begin{array}{l}\text { Record length } \\
\text { (days) }\end{array}$ & $\mathrm{C}_{\mathrm{d}} \times 10^{3}$ & $r^{2}$ \\
\hline 1 & 25 & 0.55 & 1 & 1.2 & 0.85 \\
\hline 2 & 110 & 0.19 & 7 & 1.0 & 0.66 \\
\hline 3 & 19 & 0.65 & 51 & 1.0 & 0.69 \\
\hline 4 & 30 & 0.56 & 3 & 1.3 & 0.81 \\
\hline $5 \mathrm{i}$ & 23 & 0.50 & 49 & 0.7 & 0.59 \\
\hline $5 \mathrm{ii}$ & 23 & 0.50 & 27 & 0.9 & 0.79 \\
\hline 6 & 41 & 1.46 & 29 & 1.9 & 0.94 \\
\hline 6 & 41 & 1.46 & 26 & 1.6 & 0.88 \\
\hline 7 & 22 & 0.36 & 8 & 0.6 & 0.62 \\
\hline
\end{tabular}



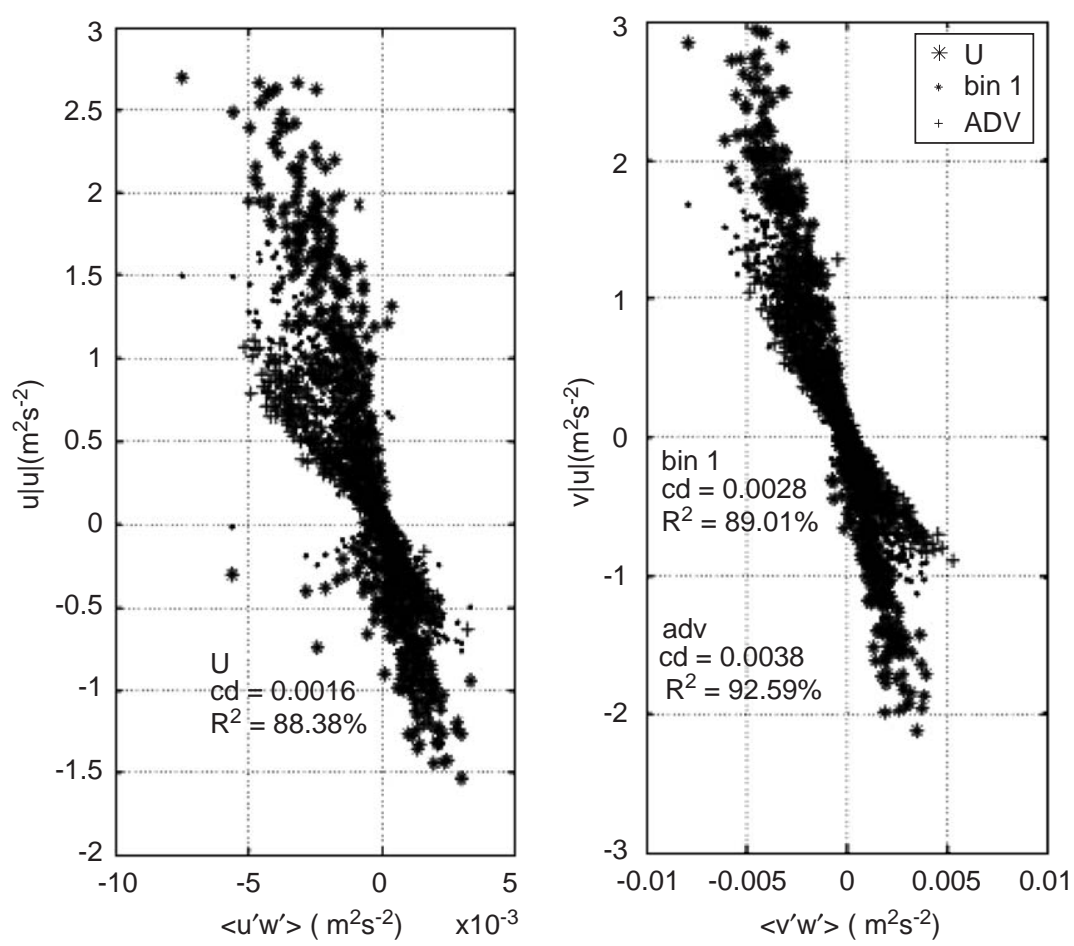

Fig. 6. Scatter plot of Reynolds stress from the bottom ADCP bin against $|u| u$ (depth-averaged, asterisk), bin 1 (dot) and Reynolds stress from the ADV vs. depth-averaged $|u| u$ (plus) from the Holyhead (site 6ii).

where $u_{*}$ is the friction velocity; $z_{0}$, as already described, is the roughness length and the bottom stress, $\tau_{b}=\rho u_{*}^{2}$. Whilst a log profile can be fitted to most approximately stationary tidal-current profiles, interpretation of the results is more difficult. Indeed, logarithmic profiles are commonly observed occupying a thicker layer above the bed than would be expected from their derivation in a constant stress layer. As seen above, $z_{0}$, the height at which the current is zero, is millimetres or less whilst for water column measurements, even with ADCPs in sea-bed frames, the bottom current measurement is usually over $1 \mathrm{~m}$ and often several metres above the sea bed. In addition, $u_{*}$ and $z_{0}$ values can change depending on the number of bins included. Whilst fits tend to show consistent $u_{*}$ values, $z_{0}$ values are much larger than expected and very scattered. The $u_{*}$ and hence corresponding drag coefficients calculated in this way are higher than calculated from the Reynolds stresses, by up to an order of magnitude, perhaps being

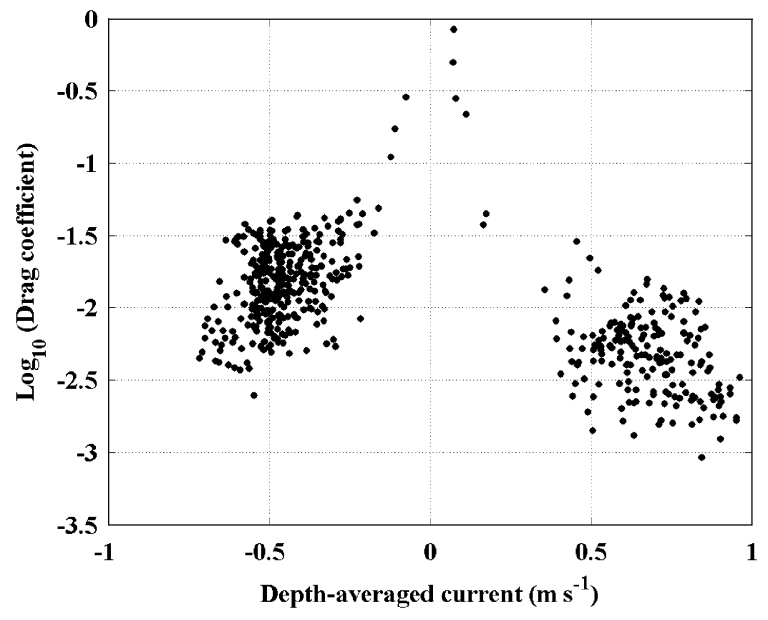

Fig. 7. Drag coefficient calculated from logarithmic profiles fitted to ten $1 \mathrm{~m}$ bins for deployment 5i, where $r^{2}>0.975$.

representative of larger-scale processes. These difficulties can be seen in Fig. 7, showing drag coefficients calculated from $u_{*}$ obtained from 


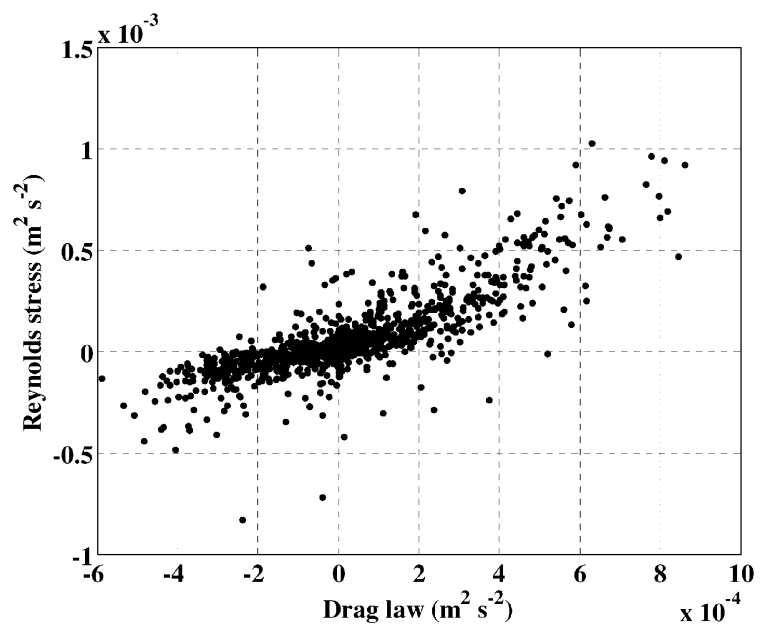

Fig. 8. Scatter plot for deployment 5 i of bottom ADCP bin (at $2.64 \mathrm{~m}$ ) east component of Reynolds stress against east component of $0.001 \mathbf{u}|\mathbf{u}|$.

fitting logarithmic profiles to the bottom ten $1 \mathrm{~m}$ bins for deployment 5i. Values are only shown where $r^{2}$ for the fit exceeded 0.975. There is a large amount of scatter in the values (in the range $0.01-0.001$ for the flood and $0.03-0.003$ for the ebb).

At some sites the estimated drag coefficient differed between ebb and flood flows. This is shown consistently at the Liverpool Bay site (5), Fig. 8 and also Fig. 2. Fig. 8, a scatter plot of the east component of bottom stress (the tides were rectilinear, approximately east-west) plotted against $0.001 \mathrm{u}|\mathbf{u}|$, shows a larger slope for the flood as against the ebb flow. (Note that drag coefficients from logarithmic profiles for the same data set are shown in Fig. 7, showing asymmetry between ebb and flood but in the opposite sense.) At this site the flood flow itself is stronger than the ebb. The lack of symmetry between ebb and flood estimated drag coefficients may be related to the bottom topography, as yet unknown - an experiment will shortly be taking place to determine the topography.

\section{Conclusions}

This paper, together with Howarth $(2002,2003)$ and Souza and Howarth (2005), by comparison with direct estimates from fast-sample electro-magnetic current meters and ADVs, has demonstrated that the along-beam variance method of estimating bed stress and Reynolds stress is reliable in continental shelf seas over a range of tidal conditions $\left(0.19<\max M_{2}\left(\mathrm{~m} \mathrm{~s}^{-1}\right)<1.46\right)$ when wave activity is low. The mean drag coefficient for depth-averaged currents was calculated to be 0.0011 , low compared with values used in depth-averaged numerical models, with an indication that the drag coefficient varies with the tidal current speed.

\section{Acknowledgements}

This work was supported by the European Union's MAST program under contract MAS3CT97-0159 (Processes of Vertical Exchange in Shelf Seas), by the UK Natural Environment Research Council (NERC)/Ministry of Defence Joint Grant Scheme and by NERC Grant (NER/ $\mathrm{M} / \mathrm{S} 0076$ ). The Gulf of California measurements were partly funded by ONRIFO Visiting Fellow Grant no. NOOO14-02-1-4031.

\section{References}

Bowden, K.F., Fairbairn, L.A., 1956. Measurement of turbulent fluctuations and Reynolds stresses in a tidal current. Proceedings of the Royal Society of London, Series A 237, 422-438.

Davies, A.M., Kwong, C.M., Flather, R.A., 1997. A threedimensional model of diurnal and semi-diurnal tides on the European Shelf. Journal of Geophysical Research 102 (C4), 8625-8656.

Flather, R.A., 1976. A tidal model of the north-west European continental shelf. Memoires de la Society Royal des Sciences de Liege, 6 ser, 10, 141-164.

Gross, T.F., Nowell, R.M., 1983. Mean flow and turbulence scaling in a tidal boundary layer. Continental Shelf Research 2, 109-126.

Howarth, M.J., 2002. Estimates of Reynolds and bottom stress from fast sample ADCPs deployed in continental shelf seas. In: Wahl, T., Pugh, C., Oberg, K., Vermeyen, T. (Eds.), Proceedings of Conference on Hydraulic Measurements \& Experimental Methods 2002. ASCE, New York, p. 10.

Howarth, M.J., 2003. ADCP estimates of Reynolds and bottom stress. In: Rizoli, J. (Ed.), Proceedings of the IEEE/OES Seventh Working Conference on Current Measurement Technology, March 2003. The Printing House, Stoughton, WI, pp. 219-224. 
Lohrmann, A., Hackett, B., Røed, L.P., 1990. High resolution measurements of turbulence, velocity and stress using pulseto-pulse coherent sonar. Journal of Atmospheric and Oceanic Technology 7, 19-37.

Lu, Y., Lueck, R.G., 1999. Using a broadband ADCP in a tidal channel. Part II: turbulence. Journal of Atmospheric and Oceanic Technology 16, 1568-1579.

Lu, Y., Lueck, R.G., Huang, D., 2000. Turbulence characteristics in a tidal channel. Journal of Physical Oceanography 30, 855-867.

Lueck, R.G., Lu, Y., 1997. The logarithmic layer in a tidal channel. Continental Shelf Research 17, 1785-1801.

RDI, 2000. Application Note FSA-003-Broadband ADCP Water Profiling Modes. RDI, San Diego.

Rippeth, T.P., Williams, E., Simpson, J.H., 2002. Reynolds stress and turbulent energy production in a tidal channel. Journal of Physical Oceanography 32, 1242-1251.

Rippeth, T.P., Simpson, J.H., Williams, E., Inall, M.E., 2003. Measurement of the rates of production and dissipation of turbulent kinetic energy in an energetic tidal flow: red Wharf Bay revisited. Journal of Physical Oceanography 33, 1889-1901.
Soulsby, R.L., 1980. Selecting record length and digitization rate for near-bed turbulence measurements. Journal of Physical Oceanography 10, 208-219.

Soulsby, R.L., 1983. The bottom boundary layer of shelf seas. In: Johns, B. (Ed.), Physical Oceanography of Coastal and Shelf Seas, vol. 35. Elsevier Oceanography Series, pp. 189-266.

Souza, A.J., Howarth, M.J., 2005. Estimates of Reynolds stress in a highly energetic shelf sea. Ocean Dynamics, in press.

Souza, A.J., Alvarez, L.G., Dickey, T., 2004. Tidally induced turbulence and suspended sediment. Geophysical Research Letters 31, L20309, in press, doi:10.1029/2004GLO21186.

Stacey, M.T., Monismith, S.G., Burau, J.R., 1999. Measurement of Reynolds stress profiles in unstratified tidal flow. Journal of Geophysical Research 104 (C5), 10,933-10,949.

Williams, E., Simpson, J.H., 2004. Uncertainties in estimates of Reynolds stress and TKE production rate using the ADCP variance method. Journal of Atmospheric and Oceanic Technology 21 (3), 347-357.

Wolf, J., 1999. The estimation of shear stresses from near-bed turbulent velocities for combined wave-current flow. Coastal Engineering 37, 529-543. 